\title{
How and what others are doing in competitive intelligence: various $\mathrm{CI}$ models
}

\author{
Marié-Luce Muller \\ IBIS Business and Information Services \\ mlm@ibis.co.sa \\ www.ibis.co.sa
}

\section{Introduction}

The columns on competitive intelligence (CI) for 2009 focus on models for CI and how companies use such models. As stated in the previous columns, seldom do two CI practices resemble one another. The reasons are multiple but perhaps the most logical reason is that no two companies are the same. They differ in size, the industry they play in, the manner in which they compete, their competitive strategies, the people and skills and many other reasons. There is no single model. It would perhaps be useful to continue focusing articles in 2009 on examining various CI model approaches and practices in a variety of companies differing in size, industry and structure.

The most important role in any CI capability is that of its internal CI unit. The CI unit or organisation is responsible for direction, collection, evaluation and analysis of raw data, and preparation, presentation and dissemination of CI (Fleisher and Bensoussan 2002). Such a CI unit can be self-reliant or may task others in the company to assist, or even approach external CI suppliers or contractors. The CI unit is tasked to prioritise key intelligence needs, to decide upon sources of information, collection strategies, data and information organisation and, most importantly, the unit is responsible for centralising information and then analysing, interpreting and communicating intelligence.

Other decisions may involve a choice of specialised interest groups (such as academics, trade associations and consumer groups), private sector sources (competitors, suppliers, distributors, customers) or the media as the sources of information. Such decisions are informed by factors such as time, budgets, skills and the nature of the intelligence need (Malhotra 1996).

\section{Basic CI models}

Without a proper and appropriate intelligence process and structure, it is difficult to develop intelligence in a company (Du Toit and Muller 2004). Du Toit and Muller (2004) mention a number of factors that impact on the type of model that companies implement. Strategic versus tactical needs, the nature of a company's structure and decision-making model lead companies to choose from three basic general organisational structures for the intelligence function: a centralised function that reports to a single corporate entity; a decentralised function that typically incorporates multiple intelligence units serving several organisational components; or a hybrid function that combine features of both centralised and decentralised functions (Gilad and Gilad 1986:54). Increasingly, however, other models are emerging related to the outsourcing of even key functions of CI (Eaton 2004). Yet, deciding on the right model for CI is a challenge. CI leader, Motorola's former Chairman Bob Galvin said multinationals need their own intelligence programme if they are to operate and compete successfully. Importantly, Galvin added that CI required only a small unit of professionals to 
be successful, but not 'amateurs or part-timers' (Galvin 2001).

Du Toit and Muller (2004) and Miller (2000:50) intimate that intelligence functions have a variety of needs that must be met in order for intelligence to render measurable results. These needs fall into five broad categories: access to decision-making structures to support decision making by providing competitive insights; discussing alternatives, and compelling action; sufficient visibility and recognition as a vital, legal, and ethical support unit (McGonagle and Vella 1999:173); linkage to other parts of the company (the majority of information that can be transformed into intelligence resides within most companies and if an intelligence unit is unable to access and acquire this internal information due to poor organisational location, it will not be able to conduct intelligence operations properly); and sufficient funding and nurturing. Besides the necessity of a sufficient budget it has been found that companies often fail to support the CI unit properly. Intelligence units that will make a difference are those that have adequate staff, technology and other support (Miller 2000:52).

Table 1 provides a framework that companies pursuing an intelligence programme can use to help guide their decision as to where to locate the unit.

Table 1 Organisational models (Source: Miller 2000:47)

\begin{tabular}{|l|l|l|l|}
\hline & $\begin{array}{l}\text { Strategic } \\
\text { vs. } \\
\text { tactical }\end{array}$ & $\begin{array}{l}\text { Corporate } \\
\text { organisational } \\
\text { structure }\end{array}$ & $\begin{array}{l}\text { Locus of } \\
\text { decision } \\
\text { making }\end{array}$ \\
\hline Centralised & $\begin{array}{l}\text { Weigh } \\
\text { toward } \\
\text { strategic } \\
\text { focus }\end{array}$ & $\begin{array}{l}\text { Strong } \\
\text { corporate staff }\end{array}$ & $\begin{array}{l}\text { Little } \\
\text { empowerment }\end{array}$ \\
\hline Decentralised & $\begin{array}{l}\text { Weigh } \\
\text { toward } \\
\text { tactical } \\
\text { focus }\end{array}$ & $\begin{array}{l}\text { Highly } \\
\text { autonomous } \\
\text { business units }\end{array}$ & $\begin{array}{l}\text { Complete } \\
\text { empowerment }\end{array}$ \\
\hline Hybrid & $\begin{array}{l}\text { Mix of } \\
\text { strategic } \\
\text { and } \\
\text { tactical } \\
\text { needs }\end{array}$ & $\begin{array}{l}\text { Balance of } \\
\text { power among } \\
\text { corporate and } \\
\text { divisional } \\
\text { staffs }\end{array}$ & $\begin{array}{l}\text { Consensual } \\
\text { decision } \\
\text { making }\end{array}$ \\
\hline
\end{tabular}

Gilad (2001) argues that the debate on where best to locate the CI professional is ongoing. He says many older world companies traditionally place the CI unit under other functions and thereby limit its scope to a narrow functional focus. Ideally it should sit atop line functions which it should regard as its building blocks. Gilad argues that some line functions are worse than others in terms of their impact on CI. The table below illustrates Gilad's ranking of functional locations, and a few comments on each (Gilad 2001).

Table 2 Ranking of CI's functional location (Source: Gilad 2001)

\begin{tabular}{|l|l|l|l|}
\hline $\begin{array}{l}\text { Rank by } \\
\text { effectiveness }\end{array}$ & $\begin{array}{l}\text { Functional } \\
\text { location }\end{array}$ & $\begin{array}{l}\text { Main } \\
\text { weakness }\end{array}$ & Main benefit \\
\hline
\end{tabular}




\begin{tabular}{|l|l|l|l|} 
& & & \\
\hline 1 (highest) & $\begin{array}{l}\text { None } \\
\text { (independent } \\
\text { CCO or CRO } \\
\text { position 1) }\end{array}$ & Politics & $\begin{array}{l}\text { Effect on } \\
\text { company's } \\
\text { overall risk } \\
\text { level }\end{array}$ \\
\hline 2 & $\begin{array}{l}\text { Strategy } \\
\text { Department }\end{array}$ & $\begin{array}{l}\text { Secondary } \\
\text { priority }\end{array}$ & Focus \\
\hline 3 & $\begin{array}{l}\text { Marketing } \\
\text { Department }\end{array}$ & Wrong focus & Tactical effect \\
\hline 4 & $\begin{array}{l}\text { Market Research } \\
4\end{array}$ & $\begin{array}{l}\text { Differing } \\
\text { focus areas }\end{array}$ & None \\
\hline 5 (lowest) & $\begin{array}{l}\text { Knowledge } \\
\text { Management } \\
(\text { KM })^{5}\end{array}$ & Focus on IT & None \\
\hline
\end{tabular}

${ }^{1}$ Independence is the most realistic reaction to the need to coordinate cross-functional response to structural changes at the industry level - reporting to the unit president or general manager.

${ }^{2}$ Strategy Department location's benefits include that CI people get to deal with strategic issues.

${ }^{3}$ Marketing: CI under a marketing executive's control is too often strictly tracking of competitors, focused on tactical information (product, pricing, etc.), and is mostly news reporting

${ }^{4}$ Market Research (MR): CI is fundamentally different from market research. MR focuses on the consumer/customer, uses neutral primary research (behavioural or focus groups), employs sophisticated statistical analysis, and is heavily biased towards quantitative results (market-share statistics, cluster analysis, multivariate models). MR is one of many inputs to CI, as CI focuses on the risks in the industry arena and beyond (alternative technologies, substitutes, potential entry).

${ }^{5}$ Knowledge Management: according to Gilad, placing CI under KM is a 'certain kiss of death' (Gilad 2001).

\subsection{Centralised intelligence units}

In centralised CI units, actions such as the collection, interpretation, analysis and communication of CI have been assigned to specialised intra organisational intelligence or competitor analysis units in order to exploit the synergy created by centralisation (Pirttilä 1998:79). Centralised units typically report to a senior corporate officer who is responsible for providing the necessary guidance and assistance for the intelligent process in terms of budgets, personnel and other resources (Miller 2000:48). Advantages of centralised units include the ease with which data can be assembled and shared, since all divisions transmit their information to a single, organising unit (Greene 1988:288).

Johnson (2005) however states that centralised, command-and-control CI practices have been 
called into question by the very theories driving modern decision science. CI must also adapt to new models and adopt the principles of instinctive as well as collective decision making in an era of ruthless, winner-take-all competitive pressure.

\subsection{Decentralised intelligence units}

Decentralised units typically include the distribution of CI professionals throughout the company where they mainly serve tactical intelligence requirements, and seldom provide intelligence to senior management (Miller 2000:49). Any centralised CI unit has the responsibility of coordinating intelligence activities among the other intelligence units. The division intelligence priorities and information is rarely shared with other business units leading to a silo problem. This is often not economical as a model as there is duplication of the effort. Furthermore, such a model does not support the development of a coordinated and informed view developing about opportunities and threats. CI depends on the convergence of data to function properly and, with a decentralised unit, that confluence is much more difficult to achieve (Greene 1988:288). On the other hand, the advantage of a decentralised unit is its dependence on interpersonal networking (often individuals mix with others perceived to be outside their natural professional constituency) that leads to information sharing and spontaneous team building (Hall 2000:141).

\subsection{Hybrid intelligence units}

Hybrid units combine attributes of both centralised and decentralised units (Du Toit and Muller 2004).

\section{Outsourced model}

The aforementioned models are all internally managed and executed. Internal CI staff, spending their time evaluating the competitive landscape of a company, often leads to weaknesses in the intelligence due to various reasons. These could include the following:

- The emergence of myopic views leads to the CI unit providing a single dimensional view of any given competitive situation. Failing to include the views of other functional experts could lead to shallow intelligence.

- CI units that lack interaction with other departments or business units and even external sources become isolated from new developments and processes that place any given competitive activity within its larger context.

- Isolated internal CI units often do not sufficiently interact with external stakeholders of the company, for exampe customers, suppliers and other third-party experts. Such units then lack real input into their intelligence and insight.

These problem areas have given rise to two outsourced models, namely the outsourced CI project model or the complete third-party model (Eaton 2003)

Outsourcing is typically considered when cost cutting is taking place but also when the necessary support from top management is lacking. Having high-level management on board is critical to a successful CI function (Fleisher and Bensoussan 2002; Miller 2000). In such cases, obtaining an external view and assistance will be beneficial. Outsourcing is also considered in cases where $\mathrm{CI}$ is performed as an additional function. Outsourcing will be beneficial in terms of resources, time and expertise. CI is not a part-time activity, yet, it is often thrown into an activity basket that also contains market research, library services, information searches, networking, internal debriefings and internal CI coordination. A benefit of outsourcing to a supplier that specialises in real CI is that they will provide forward looking analysis and opportunities analyses that go far beyond simple librarian-style 
information.

Outsourcing is also considered in cases where certain information is unavailable or difficult to access from an internal CI unit's point of view, or when companies might feel uncomfortable to gather certain information, or when key external expertise is required. The best legally attainable intelligence is available within a company and from a company's customers, suppliers and people in the field, including sales and marketing people and merchandisers. However, often CI personnel are discouraged to talk to such external sources and, if they were permitted to do so, it would be difficult to obtain honest views. This is an aspect that Motorola has recognised and rectified. It ensured that the sales force is integrated with the corporate intelligence network (Galvin 2001). Outsourcing CI presents no barrier to the ethical collection of data from external experts (Eaton 2003).

According to Eaton (2003) and Johnson (2005), there are advantages and disadvantages to the outsourcing model. The advantages include an enhanced external objectivity and a professional stature within the client, unattainable by lower level internal employees, access to specialist processes, skills and tools and the openness to contact customers, suppliers and other professionals who are often shielded from interaction with internal staff. Outsourcing also helps create a larger strategic context into which the competitive data are placed. Most CI focuses upon the threats to the company represented by specific competitive activity but, often, a threat could also give rise to an opportunity for the company. Such opportunities are often neglected. The outsourced CI professional might be bolder in providing alternative outcomes to a competitive situation. This added analysis of the implications of the data could be a valuable resource.

Experts argue that perhaps the most significant advantage of outsourcing is the building of a longer-term CI capability (Eaton 2003; Malhotra 1996). Having a long-term relationship with an external third party consulting resource means that that resource is available to build a larger awareness capability throughout the company that contracts for its services. The CI professional creates training programmes and internal seminars to insure that more of the company's functions are sensitised to the competitive environment.

Companies that may consider outsourcing CI should be aware of the potential problems that exist when outsourcing CI or when considering an external third party project oriented CI capability. CI vendors may lack the unique company view and knowledge on an industry. CI vendors are also not given the necessary access to place a given specific competitive intelligence issue within the broader strategic context of the category or the client. Furthermore, outsourced projects are often short-term focused interventions, resulting in the client company being left without significant new skills, knowledge and CI aptitude. Experience has taught that CI vendors rarely get a second opportunity to leverage the information collected during the first project for the longer-term value of the client company. A CI vendor would typically focus only on the narrow issues described in the project scope, perform the study, and deliver the results and leave (Eaton 2003). The failure to install a process that puts the immediate competitive threat within its broader strategic context or leave behind an empowered organisation makes the outsourced CI project approach inefficient. Outsourcing can also be costly and often does not provide the expected return on investment mainly due to weaknesses in scoping. A large expense item that renders only limited if any value, are generic research reports. Whereas these might go some way in providing context and a solid foundation, such reports will not provide unique insights.

There are two basic outsourced models, namely outsourcing parts of the CI function (e.g. certain projects or the gathering for primary information or even training and database management) or comprehensive outsourcing where a dedicated external function or supplier takes care of all the CI functions of a company with only a single person or small unit in the 
client company left to fulfil a coordinator role.

\subsection{Outsourced CI project model}

Outsourcing elements of CI has become increasingly popular due to various reasons, including the pressure to cut cost. The CI unit is often regarded as a cost centre and falls victim to personnel cuts. Yet the intelligence is still required and this leads to CI outsourcing. The Internet and the availability of general information have had a negative effect on the size of CI units (Eaton 2003). Pressure on CI units to deliver unique insights and not general information available freely on the Internet and other public sources has also increased due to financial pressure. According to Eaton (2003), CI has been reduced to two unacceptable alternatives: inexperienced lower-level employees delivering intelligence to senior line managers with strongly held opinions regarding the competitors that such subordinates are monitoring; or external consultants approached to address specific projects without a full understanding of their client company and no long-term investment in the company's success. As mentioned previously, such interventions have no lasting benefits to the client company that often has invested large amounts in such projects.

\subsection{Complete outsourced CI model}

Outsourcing the complete CI responsibility to a permanent external third party is the second outsourcing model (Eaton 2003). Companies are realising that higher grades of CI outsourcing are leading to higher quality service at a lower cost, primarily because of the economies of scale for the external company and that company's significant advantages in hiring and keeping expert employees in the outsource function. The availability of skills is a factor that increasingly leads to companies outsourcing CI or aspects of CI. CI specialists are scarce and retaining such talent is costly. Therefore the outsourcing option is lucrative.

\section{Conclusion}

This column discusses the various models for CI. There seems to be a shift away from purely internal CI function, albeit centralised, decentralised or a hybrid unit, towards more outsourcing of aspects of CI or total outsourcing. In the current economic climate, this trend seems to represent a viable solution to the intelligence needs of companies. Besides the various advantages to outsourcing, there are certain challenges that should be borne in mind, including cost, access to the right CI vendors and ensuring optimal return on investment.

\section{References}

Du Toit, A.S.A. and Muller, M.L. 2004. Organizational structure of competitive intelligence activities: a South African case study. South African Journal of Information Management, 6 (3). [Online]. Available WWW: http://www.sajim.co.za.

Eaton, E. 2003. Competitive intelligence: should it be permanently outsourced now? Current Dilemma and Possible Solution. [Online]. Available WWW: www.eleanoreaton.com.

Fleisher, C.S. and Bensoussan, B.E., 2002. Strategic and competitive analysis: methods and techniques for analyzing business competition. New Jersey: Prentice-Hall.

Galvin, C. 2001. What do you know and how do you know it? [Online].

Available WWW. http://www.academyci.com/News/IntelligenceAward/motorola.html.

Gilad, B., 2001. Next step in the evolution of competitive intelligence, academy of competitive intelligence. [Online]. Available WWW www.academyci.com . 
Greene, H.F. 1988. Competitive intelligence and the information center. Special libraries 79 (4):285 - 295.

Hall, H. 2000. Online information sources: tools of business intelligence? Journal of information science 20(3):139 - 143.

Johnson, A. 2005. Decisions, decisions ... competitive intelligence for predictive decision support and market risk management. [Online]. Available WWW: www.kmworld.com.

Malhotra, Y. 1996. Competitive intelligence programs: an overview. [Online]. Available WWW: www.kmbook.com/ciover.htm.

McGonagle, J.J. and Vella, C.M. 1999. The Internet age of competitive intelligence. London: Quorum Books.

Miller, J. 2000. Millennium intelligence: understanding and conducting competitive intelligence in the digital age. Menford, N.J.: CyberAge Books.

Pirttilä, A. 1998. Organising competitive intelligence activities in a corporate organization. Aslib proceedings 50 (4): 79-84.

\begin{abstract}
About the author
Marié-Luce Muller is a consulting CI analyst with IBIS Business and Information Services (Pty) Ltd, a leading Pretoria-based CI consultancy. She has a distinguished career in CI. Her primary experience lies in assisting companies in honing their CI capabilities. She also performs tracking and scanning activities on behalf of companies. Marié-Luce has published many articles on competitive intelligence (CEO Magazine, Finance Week, Business Week, Beeld, Die Burger and the South African Journal of Business Management), including an article on South Africa as an emerging CI player, which was published in an international publication of the Society of Competitive Intelligence Professionals (SCIP). She has also published a series of booklets on CI (Nuts and Bolts business series, published by Knowledge Resources) and is a member of a research team participating in an international study of CI practices among exporting companies. Previously, she was involved in research into the status of CI practices in South Africa. A member of SCIP, she holds a postgraduate degree from the University of Stellenbosch.
\end{abstract}


ISSN 1560-683X

Published by InterWord Communications for Department of Information and Knowledge Management, University of Johannesburg 